\title{
A BELEZA CIRCASSIANA NO SÉCULO XIX E A APROPRIAÇÃo CULTURAL DE PT BARNUM
}

\author{
THE CIRCASSIAN BEAUTY IN THE XIX CENTURY AND THE \\ CULTURAL APPROPRIATION OF PT BARNUM
}

DOI: http://dx.doi.org/10.15448/2178-3748.2018.1.25099

\author{
Maria Helena Alves da Silva \\ Doutoranda em Planejamento Urbano e Regional - UNIVAP/PB \\ maria.42246@yahoo.com.br
}

\begin{abstract}
RESUMO: Este trabalho tem como objetivo contribuir para os estudos acerca da sociedade norte-americana do século XIX através de uma breve análise da "beleza circassiana", termo utilizado para se referir as características físicas dos homens e mulheres originários da Circássia. Este artigo abordará questões relativas à moral norteamericana e seu interesse pela Guerra russo-circassiana, potencializados por publicações de poemas, artigos de jornais e romances publicados por autores reconhecidos do período, e sobre como empresários da área circense utilizaram esse interesse para recriar a beleza circassiana nos Estados Unidos, fazendo referência à escravidão branca e africana. O trabalho também levantará questões relativas ao interesse norte-americano do comércio de escravos estar utilizando de mulheres brancas, e como isso afetava a imaginação norte-americana e europeia. Para essa pesquisa, foram utilizados livros e artigos referentes à temática, todas escritas em inglês e sem tradução para o português, embora tal tema seja importante para aprendermos mais como a imaginação, o ideal e a apropriação cultural eram percebidas no século dezenove.
\end{abstract}

PALAVRAS-CHAVE: Século XIX, Apropriação Cultural, Beleza Circassiana.

ABSTRACT: This work aims to contribute to the study of nineteenth-century north-american society through a brief analysis of the "Circassian beauty", a term used to refer to the physical characteristics of Circassian men and women. This article will address issues related to north-american morality and its interest in the RussianCircassian War, enhanced by poetry publications, newspaper articles and novels published by renowned authors of the period, and how entrepreneurs in the circus area have used this interest to recreate Circassian beauty in the United States, making reference to white and african slavery. The work will also raise questions about the northamerican interest in the slave trade being used by white women, and how it affected the american and european imagination. For this research, books and articles referring to the subject were used, all written in English and without translation into portuguese, although this theme is important to learn more as the imagination, ideal and cultural appropriation were perceived in the nineteenth century.

KEYWORDS: Nineteenth century, Cultural Appropriation, Circassian Beauty.

\section{PUBLICAÇÕES E RECONHECIMENTOS REFERENTES A CIRCÁSSIA ATÉ A SEGUNDA METADE DO SÉCULO XIX}

Entre 1763 e 1864 aconteceu uma série de eventos que seriam conhecidos como a Guerra russo-circassiana, parte da conquista do Império Russo do Cáucaso. Até o século XIX, o território da Circássia se transformaria em uma contenção entre as terras de dois vizinhos rivais, a Rússia e a Turquia e, eventualmente, a Circássia foi cedida pela Turquia, 
sendo então possuída pela Rússia contra sua vontade. Em seu livro "The Circassians: A Handbook", Amjad Jaimoukha, diretor do International Centre for Circassian Studies (ICCS) e considerado um dos escritores circassianos mais influentes das últimas décadas, esse foi um dos períodos históricos mais trágicos da história da Circássia: sua guerra com a Rússia terminaria apenas em 1864, após o Genocídio Circassiano (um grupo étnico do norte do Cáucaso), que teria causado a morte de até 1,5 milhão de pessoas. Muitos emigraram para os países vizinhos, como Iraque, Kosovo, Jordânia, Síria, Israel e Turquia.

Os primeiros anos da década de 1860, sendo os anos finais da guerra, envolveram o massacre da população circassiana e fez com que se tornassem o foco de muitos mitos e literatura. A poeta americana Emily Dickinson (1830 - 1886) citou-os em seu poema "Some Rainbow - coming from the Fair"; o poeta inglês Lorde Byron (1788 - 1824) descreveu a venda de uma mulher circassiana escrava em sua obra "Don Juan"; a jovem poeta americana Lucretia Davidson (1808 - 1825) escreveu um romance sobre o Rei de Kashmir e uma circassiana capturada em seu romance de 1829 "Amir Khan"; Henry Fielding (1707 - 1754), romancista inglês, escreveu em seu livro "The History of Tom Jones, a Foundling" sobre as belezas circassianas (MILLER, 2012, p. 124).

No entanto, a publicação sobre as circassianas que as tornariam mais famosas e conhecidas foi escrita pelo filósofo francês Voltaire (1694 - 1778) em suas cartas publicadas entre 1726 e 1729. Na carta XI, "On Inoculation", o autor defende a prática da inoculação citando como exemplo as mulheres circassianas que, "desde tempos imemoriais, transmitem a varíola para seus filhos quando não tem mais de seis meses de idade, fazendo uma incisão no braço" 1(VOLTAIRE, 1697-1778, parágrafo 4). O autor então introduz o povo da Circássia:

\begin{abstract}
Os circassianos são pobres, e as suas filhas são lindas, e, na verdade, é nelas que reside principalmente o comércio. Elas fornecem com suas belezas os serralhos do sultão turco, da Persian Sophy, e de todos aqueles que são ricos o suficiente para comprar e manter tal mercadoria preciosa. Essas moças são muito honrosas e virtuosamente instruídas em como agradar e acariciar os homens, são ensinadas a fazer uma dança muito educada e feminina, e aumentam, com artifícios voluptuosos, os prazeres de seus senhores desdenhosos para quem elas são enviadas. Essas criaturas infelizes repetem as lições para suas mães, da mesma maneira como as pequenas meninas entre nós repetem seu catecismo sem entenderem uma palavra do que dizem² $^{2}$. (VOLTAIRE, 1697-1778, parágrafo 4).
\end{abstract}

\footnotetext{
${ }^{1}$ Original em inglês: "[The Circassian women have] from time immemorial, communicated the small-pox to their children when not above six months old by making an incision in the arm [...]". Tradução minha.

${ }^{2}$ Original em inglês: "The Circassians are poor, and their daughters are beautiful, and indeed, it is in them they chiefly trade. They furnish with beauties the seraglios of the Turkish Sultan, of the Persian Sophy, and of all those who are wealthy enough to purchase and maintain such precious merchandise. These maidens are very honourably and virtuously instructed to fondle and caress men; are taught dances of a very polite and effeminate
} 
Como observa Madina Tlostanova, professora de filosofia da RANEPA (Russian Presidential Academy of National Economy and Public Administration), a história de mulheres brancas caucasianas sendo escravas era de particular interesse na América porque ia contra a hierarquia racial estabelecida: brancos não podiam ser escravos (TLOSTANOVA, 2010, p. 90). Além disso, "a ideia de uma mulher estar à mercê sexual de seu proprietário não era estranha à imaginação do público branco no momento nos Estados Unidos"3: afinal de contas, os proprietários de escravos norte-americanos muitas vezes tinham relações sexuais com suas escravas, e era estranho, se não horroroso, pensar que uma mulher branca poderia estar na mesma situação (FRIED, 2013, s.p.).

Em 1855, o escritor inglês William Makepeace Thackeray (1811 - 1863), mais conhecido pela sua obra satírica Vanity Fair, começou a publicar uma novela chamada "The Newcomes", cujos eventos ocorriam em países e períodos diversos. Uma das personagens, Ethel, descreve a si mesma como uma escrava circassiana: "Nós somos tanto vendidas quanto as mulheres turcas; a única diferença é que nossos mestres podem ter apenas uma circassiana por vez"4 , e outro personagem menciona que uma beleza circassiana pode ser comprada por menos de mil moedas; Christina, outra personagem, comenta que ela teme que seu cabelo tenha sido danificado, o que faria com que ela fosse vendida por menos (MCMASTER, 1978, p. 407).

Diversos artigos começaram a ser publicados condenando o Islã e a Turquia por conta da escravização branca: o artigo "Horrible Traffic in Circassian Women - Infanticide in Turkey", publicado no New York Daily Times, em 6 de Agosto de 1856, é um bom exemplo desse tipo de publicação. Nesse caso, o jornal descrevia o comércio escravista em detalhes e especulava que as crianças não desejadas, filhos de escravas africanas e senhores turcos estavam sendo mortas por conta dos gastos, ou sendo vendidas para que seus senhores pudessem comprar belas meninas circassianas. Como observa Tlostanova, esse e outros artigos deixavam implícito que, enquanto antigamente apenas os ricos poderiam comprar escravos, agora as classes baixas poderiam comprar até mesmo mulheres brancas - o que é mostrado como imoral, inumado e não-cristão (TLOSTANOVA, 2010, p. 90)

kind; and how to heighten by the most voluptuous artifices the pleasures of their disdainful masters for whom they are designed. These unhappy creatures repeat their lesson to their mothers, in the same manner as little girls among us repeat their catechism without understanding one word they say”. Tradução minha.

${ }^{3}$ Original em inglês: "The idea of a woman being at the sex-ual mercy of her owner was not for-eign to the imag-i-na-tion of the white pub-lic at the time in the United States". Tradução minha.

${ }^{4}$ Original em inglês: "'"'We are sold," the young girl went on, "we are as much sold as Turkish women; the only difference being that our masters may have but one Circassian at a time". Tradução minha. 
Mas o interesse na Circássia não era apenas por conta da guerra e suas mulheres. No século XVIII, o antropólogo alemão Johann Friedrich Blumenbach (1752 - 1840) viu em um esqueleto humano encontrado nas montanhas da Carcássia características que ele havia idealizado como particular dos germânicos. Dessa forma, Blumenbach fez uma ligação entre o povo germânico e o povo circassiano (MARTIN, 2002, p. 103). Convencido de que todos os humanos tinham uma origem em comum, Blumenbach cunhou o termo "caucasiano" e conjeturou que todos os humanos tinha origem do Cáucaso, e não só os europeus (BOGDAN, 2014, p. 200).

Como nota Charles King, professor de Relação Internacionais e de Governo da Universidade de Georgetown, qualquer europeu educado acreditava que os circassianos eram a versão asiática dos europeus aristocráticos, com uma sociedade hierarquicamente organizada, com escravos e um forte príncipe reinando sobre os nobres; além disso, acreditava-se que seus guerreiros iam para a guerra com cotas de malha, o que o fizeram ser identificados como guerreiros perdidos das Cruzadas e sendo percebidos como remanescentes dos cavaleiros medievais (KING, 2007, p. 242).

A ideia de um povo europeu branco perfeito, com grandes ligações com os europeus, continuou a reforçar a ideia da supremacia branca e, dessa forma, podemos entender a revolta do povo europeu e norte-americano ao vivenciarem a escravização do povo branco e ideal da Circássia, principalmente as mulheres.

Outra preocupação dos europeus e norte-americanos era a mistura de raça: acreditavase que homens mongóis queriam casar com as mulheres carcassianas, mesmo sendo de famílias pobres, por causa de sua beleza superior. Dessa forma, as mulheres brancas do Cáucaso (a partir de que, acreditava-se, todas as raças se originavam) estavam sendo casadas para que outras etnias 'melhorassem' sua aparência (FIGAL, 2014, p. 179). Isso pode ser notado na publicação de 1854 "Various Tribes of the Human Race", na revista The Illustrated Magazine. O autor diz que os turcos, "vistos sem preconceito", são sujeitos nobres, mas sua fisionia era inferior na beleza: mas então porque, naquele momento, os turcos eram geralmente bonitos? A causa era atribuída ao casamento inter-racial de seus antecessores com uma "raça mais favorecida que a sua própria" e, como resultado, "os modernos otomanos agora possuem mais da metade das características da raça caucasiana ${ }^{5 "}$ (VARI, 1854, p. 223). O autor continua que o mesmo pode ser dito dos habitantes do vale de Caxemira, cujos

\footnotetext{
5 Original em inglês: "Viewed without prejudice"; "[a race] more favoured by nature than their own"; "the modern Ottoman now possesses more than half the characteristics of the Caucasian race". Tradução minha.
} 
nativos eram agora de bonita compleição, graças ao casamento inter-racial com garotas carcassianas.

Como observou o professor da Universidade de Suffolk, Gregory Fried,

A lenda da mulher circassiana envolvia um componente provocativo para os americanos brancos: a idéia de que os circassianos eram a forma mais primordial da raça branca e , portanto, eram os exemplares mais belos e puros da brancura, especialmente as suas mulheres; mas, ao mesmo tempo, essas mulheres circassianas eram sujeitas ao tráfico de escravos do Império Otomano. A idéia de que uma mulher branca pode ser vendida como escrava e, especialmente, vendida em uma escravidão que a marcaria como um objeto sexual no harém de um potentado, era uma questão tanto de horror e fascínio moral transgressor para a imaginação branca $^{6}$ (FRIED, 2013, s.p.).

\section{PT BARNUM E SUA APROPRIAÇÃO DA HISTÓRIA CIRCASSIANA}

Aproveitando a popularidade dessas publicações e de sua polêmica, Phineas Taylor Barnum (1810 - 1891) capitalizou esse interesse ao começar a exibir mulheres circassianas em seus shows. Barnum, nascido em 1810, cresceu em uma era que escarnecia de rituais antigos, com uma geração que desafiava as noções de ordens sociais que estavam intocadas há séculos e que viam novos homens colocados na ordem moral, social e até mesmo religiosa (HARRIS, 1981, p 3). Como observou o autor Neil Harris, historiador social da Universidade de Chicago, em uma época em que brasões de armas, credenciais ou graduações em universidades não mais eram sinônimos de verdades absolutas, era difícil saber no que e em quem acreditar, e Barnum pareceu "ser o símbolo supremo dessa mudança", ao notar que "uma nova sensibilidade democrática havia nascido, e ele apelava diretamente para suas vaidades e conceitos ${ }^{7 "}$ (HARRIS, 1981, p. 4).

Em 1865, no final da Guerra Civil norte-americana, Barnum começou a exibir mulheres com a já conhecida "beleza circassianas" no seu Museu Americano. Comprado por Barnum em 1842, o "American Museum" de Barnum era uma das principais atrações da cidade de Nova York: ele reunia atrações de museus de cera, teatro, zoológico e show de horrores, instrumentos científicos e modernos, e pessoas com características consideradas curiosas, como anões, uma 'mulher gigante' e um esqueleto de sereia (KELLEY, 2000, s.p.)

\footnotetext{
${ }^{6}$ Original em inglês: "The legend of the Circassian woman involved a provocative component for white Americans: the idea that the Circassians were the most primordial form of the white race, and therefore also the purest and most beautiful exemplars of whiteness, especially their women; yet at the same time, these Circassian women were subject to the slave trade of the Ottoman Empire. The idea that a white woman might be sold into slavery, and especially sold into a slavery that marked her as a sexual object in a potentate's harem, was a matter of both moral horror and transgressive fascination to the white imagination". Tradução minha.

7 Original em inglês: "[seemed] the supreme symbol of this change", "[he was aware] that a new democratic sensibility had been born, and he appealed directly to its vanities and conceits". Tradução minha.
} 
Nos anos seguintes, as mulheres da Circássia seriam atrações populares e poderiam ser vistas por dez centavos a entrada (HORR, s.p.). No entanto, como poderia ser classificada e descrita essa beleza, uma vez que ela era entendida como a versão original do homem branco europeu? Apesar de muitas publicações fazerem referências às mulheres, poucas realmente a descreveriam. Mas dois anos antes das exibições de PT Barnum, em 1863, o escritor russo Leo Tolstoy (1828 - 1910) havia publicado seu romance "The Cossacks", na revista literária "The Russian Messenger". Traduzida apenas em 2013 para o português brasileiro, o livro conta a história um homem bem-nascido de Moscou, Dmitri Olenin, que se juntou ao exército russo no Cáucaso para escapar de sua vida superficial, acreditando que encontraria serenidade entre a população do Cáucaso. Lá, ele vê

uma garota escrava circassiana, magra, com trança longa e profundos olhos dóceis. Ele imaginou uma cabana solitária no alto das montanhas, com ela esperando na porta quando ele chegasse em casa cansado e coberto de terra, sangue e glória. Imaginou seus beijos, seus ombros, sua voz doce, sua docilidade. Ela era bonita, mas sem educação, selvagem, e áspera. Durante os longos invernos à noite ele começaria a educá-la... ela também teria um dom para línguas, leria romances franceses, e até mesmo os entenderia- ela certamente adoraria Notre-Dame de Paris. E ela seria capaz de falar francês. Em uma sala de estar, ela teria mais graça do que uma dama da alta sociedade. E ela poderia cantar - com simplicidade, força e paixão ${ }^{8}$ (KING, 2007, p. 244).

Como observa Charles King, Tolstoy escreve os atributos essenciais que se acreditava que a mulher circassiana possuiria: selvagem, inteligente, dócil: uma idiota-prodígio sexualizada (KING, 2007, p. 244).

Foi nos Estados Unidos que começou a exibição de pessoas e animais com o objetivo de fazerem parte de concursos de beleza. Barnum iniciou nesse empreendimento de concursos na década de 1850, abrangendo primeiramente crianças e animais, e então, em 1854, sugeriu que mulheres fossem ao palco para serem julgadas por sua beleza. As mulheres se recusaram a participar de tal ato e, por isso, suas fotografias de daguerreótipo eram exibidas para, então, serem votadas. Foi assim, como observa Christine Braunberger, que o público começou a se acostumar com essa forma de beleza escrutínia (BRAUNBERGER, 2000, p. 9). Ainda no romance de "The Newcomes", de Thackeray, publicado pela primeira vez em 1855, a personagem Lady Kew provoca Ethel, antes descrita como uma escrava circassiana, que "nós jovens damas do mundo, quando somos exibidas, deveríamos ter pequenos bilhetes verdes

${ }^{8}$ Original em inglês. Tradução minha. 
presos em nossas costas, com "Vendido" escrito neles; isso evitaria problemas e qualquer regateio no futuro, você sabe"9 (MCMASTER, 1978, p. 407).

No entanto, a grande verdade da exibição de mulheres circassianas de PT Barnum é que, apesar de seu sucesso, nenhuma mulher era realmente circassiana, muito menos provenientes da Turquia ou escravas. O porquê Barnum não exibia uma mulher exótica e estrangeira era muito simples: um dos maiores agentes de circo dos Estados Unidos da América não conseguiu ter acesso a elas. Em 1856, Barnum mandou seu agente John Greenwood para a Turquia para comprar uma mulher circassiana no comércio de escravos. No entanto, a escravidão já era proibida na Europa e nos Estados Unidos. Com um dilema ético e legal, Barnum enviou para David K. Htchcock uma carta falando sobre um contrato: ele compraria, sim, uma escrava da Circássia, mas ela seria liberta e ele, então, a contrataria para trabalhar (MARTIN, 2002, p. 104). Mas Barnum não obteve sucesso em sua compra, e então passou a contratar mulheres do interior dos Estados Unidos.

O termo cunhado para a apresentação dessas mulheres eram "Circassian Beauties": além de representarem o ideal do homem branco, acreditava-se que as mulheres circassianas eram dotadas de uma beleza extraordinária - como Tolstoy, pensava-se que fossem muito inteligentes, mas sem educação formal, bonitas, selvagens. No entanto, não eram exibidas fotografias nem imagens de mulheres circassianas nas publicações populares da época, de forma que ninguém sabia, realmente, como uma mulher da Circássia parecia - nem mesmo como eram suas roupas, seus costumes ou sua língua.

Assim, para não ter problemas com o público, as belezas circassianas de Barnum eram colocadas também como inacessíveis e primitivas, além de serem exibidas também como "uma forma de embaixadora cultural", como observou Linda Frost, para o humilde povo da Circássia, ameaçados pelos tirânicos russos ${ }^{10}$ (FROST, p. 250).

Zoe Meleke foi uma das primeiras e mais famosas "belezas circassianas" apresentadas ao público. Barnum publicou até mesmo um livro, de dezesseis páginas, chamado "Zoe Meleke: Biographical Sketch of the Circassian Girl" (FROST, p. 251). Para disfarçar o fato de que ela fala um inglês ordinário do interior dos Estados Unidos e sabia pouco ou quase nada da Circássia, seu suposto país de origem, Zoe era apresentada com uma mulher que

\footnotetext{
${ }^{9}$ Original em inglês: "We young ladies in the world, when we are exhibiting, ought to have little green tickets pinned on our backs, with 'Sold' written on them; it would prevent trouble and any future haggling, you know". Tradução minha.

${ }^{10}$ Original em inglês: "[but also] a kind of cultural ambassador for a humble, mountain farming people at the mercy of the tyrannical Russians". Tradução minha.
} 
Tendo muita tenra idade no momento de seu êxodo da terra de seu nascimento, suas lembranças da Circássia são, naturalmente, muito imperfeitas e obscuras, as associações de seu país distante parecem para ela um sonho imperfeito e confuso e não a realidade, e de seu longo rompimento com as pessoas de seu tipo, ela perdeu parcialmente, se não totalmente, a lembrança de sua língua nativa; e ainda, como já foi dito em outra parte deste pequeno esboço, ela fala o idioma de sua terra adotiva com uma facilidade e fluência que iria confundir o linguista mais astuto que não tivesse sido informado de outra forma para descobrir que ela não era uma nativa da América ${ }^{11}$ (NICKELL, 2005, p 193).

É provável que todas as garotas circassianas fossem apresentadas com a mesma história de Zoe: seu inglês era tão impecável que poderia ser facilmente confundida com uma nativaamericana, e ela não se lembrava de nada de sua língua ou terra nativa.

Uma vez que ela era celebrada como uma mulher sem passado, linguagem ou terra própria, com uma escrava ou pessoa primitiva sem liberdade, ela era o oposto das mulheres europeias; encarnando os ideais de corpo feminino reprodutivo, erótico e racial (FIGAL, 2014, p. 181). Como observa Sara Eigen Figal, antiga membro do corpo docente da Universidade de Vanderbilt, quando consideramos que as mulheres do Cáucaso se tornaram o ideal da mulher branca, com uma ligação comprovada da Europa, sendo o tipo original de pessoa branca, a história fica muito mais complicada: "A sexualidade escravizada da mulher branca (as evidências corporificadas da identicidade caucasiana) torna-se o espaço liminar de contágio, o local da infecção e

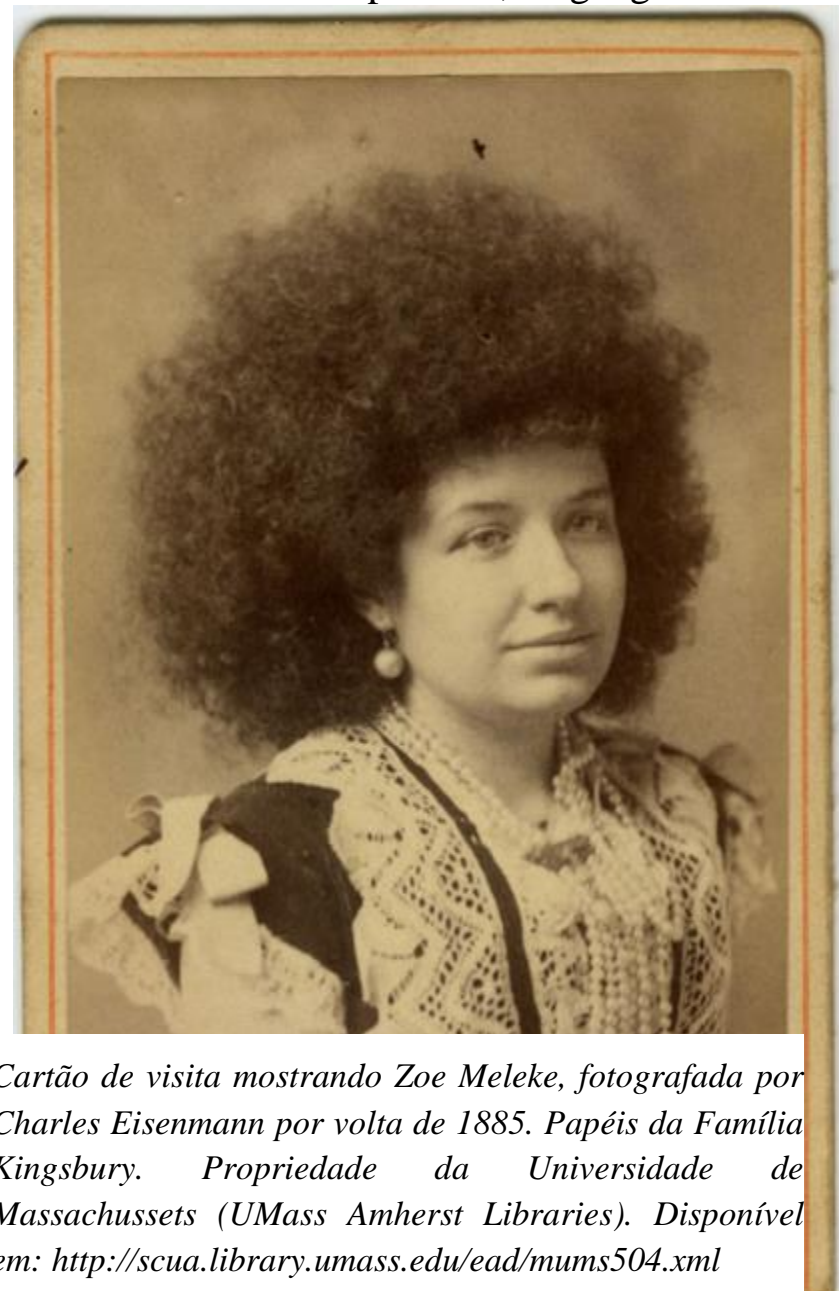

\footnotetext{
${ }^{11}$ Original em inglês: "Being a very tender age at the time of her exodus from the land of her nativity, her recollections of Circassia are of course very imperfect and obscure; the associations of her far off country seem to her an imperfect and confused dream, rather than reality; and from her long severance from the people of her kind, she has partially, if not entirely lost remembrance of her native tongue; and yet, as has been stated elsewhere in this little sketch, she speaks the language of her adopted land with an ease and fluency that would puzzle the most cunning linguist that was not otherwise informed to discover that she was not a native of America". Tradução minha.
} 
transmissão e pureza de uma só vez" ${ }^{12}$ (FIGAL, 2014, p. 182).

Ao lado, é possível ver uma fotografia de uma jovem circassiana de Barnum. Um traje inventado, provavelmente pelo próprio e sua equipe, se tornaram os modelos para as roupas das "belezas circassianas" que iam surgindo em espetáculos de circo em todo o país. Como observou Gregory Fried, as mulheres circassianas interpretadas pelas norte-americanas tinham que ter uma série de características fundamentais: deveriam ser bonitas para os padrões vitorianos, usar roupas "exóticas" - quase sempre mais reveladora do que as usadas pelas mulheres européias ou norte-americanas, com joias e bordados impressionantes e, a característica mais marcante, o penteado (FRIED, 2013, s.p.). Esse penteado extraordinário

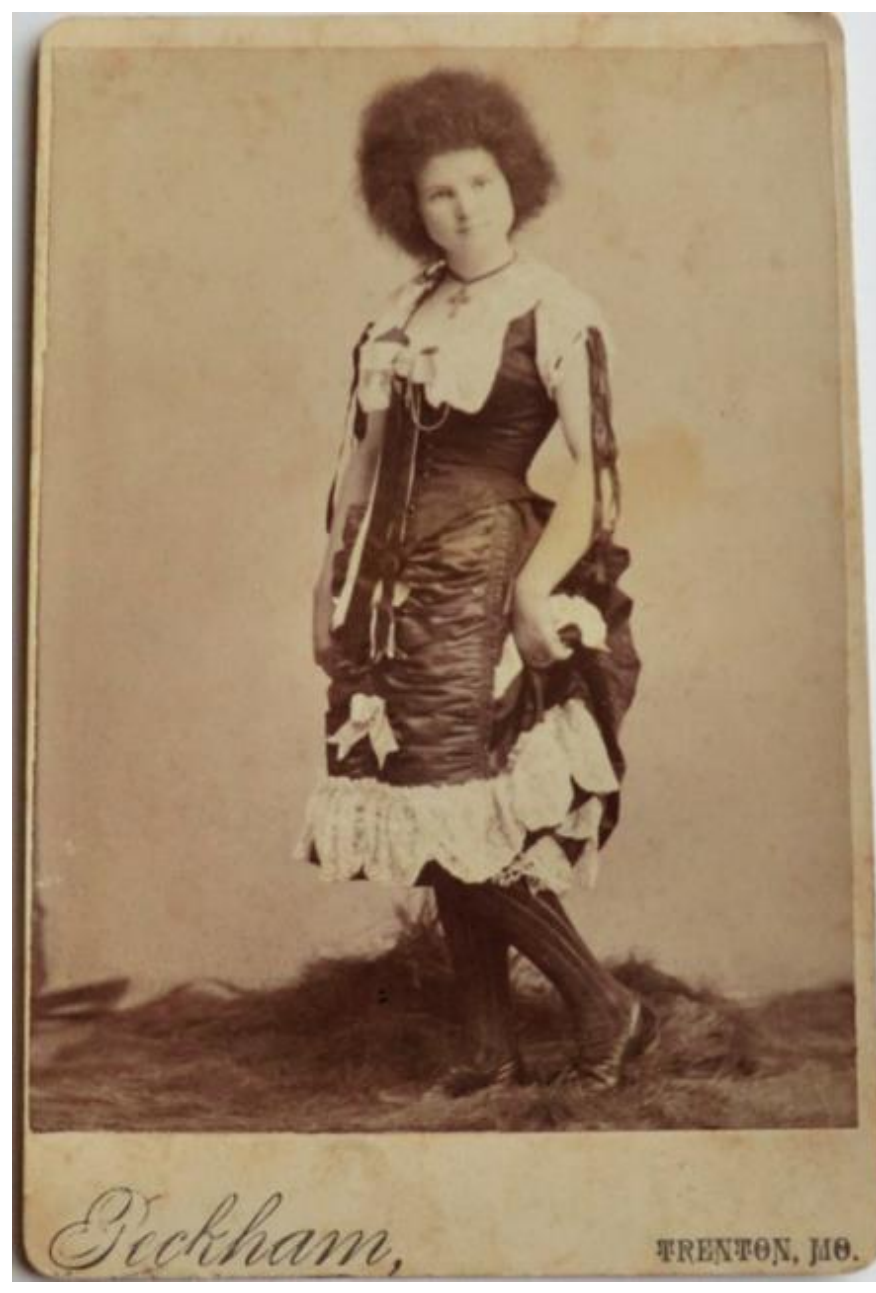

Foto de cabine mostrando Zula Zinzasa, de 17 anos. Tirada em Trenton, no Missouri. Sem data. Da coleção de Margie Kocina. Disponível em:

httns://www.etsv.com/listing/214602238/cabinet-nhoto-risaue- foi inventado inteiramente por Barnum: lavado com cerveja e depois penteado para produzir o efeito "crespo", as mulheres circassianas tinham um penteado que lembra muito o famoso "Black Power" dos anos 1960. Como nota Fried, enquanto o Afro da década de 1960 era em grande parte uma declaração da moda e rebelião contra a norma, a criação do penteado circassiano era para que as mulheres parecessem com outro, mas ainda fossem identificavelmente brancas. Há ainda outro ponto: o cabelo lembrava, sem sombra de dúvida, o cabelo africano, levantando um paradoxo. A raça branca mais pura compartilhava do cabelo dos africanos, e ambos eram sujeitos à exploração sexual. Isso é parte do que fazia as mulheres circassianas tão famosas para o espectador branco masculino: ele já sugeria a exploração sexual, e uma vez que as "mulheres africanas eram

\footnotetext{
12 Original em inglês: "[In the case of the "Circassian Beauty"], the enslaved sexuality of the white woman (the embodied evidence of Caucasian identitiy) becomes the liminal space of contagion, the site of infection and transmission and purity all at once". Tradução minha.
} 
rotineiramente retratadas com sexualmente lascivas e, portanto, em certo sentido, dispostas e cúmplices na sua exploração sexual"13, o mesmo poderia ser dito às mulheres brancas circassianas - sujeitas à exploração sexual, mas simbolizando a origem do homem branco, resgatados de seu terrível destino (FRIED, 2013, s.p.).

As fotografias das belezas circassianas após PT Barnum mostram mulheres em poses exóticas: como observa Fried, os trajes das mulheres de Barnum não tinham nenhuma relação com as roupas usadas pela verdadeiras mulheres da Carcássia; mas os trajes inventados mostravam certo orientalismo - "é oferecido ao espectador a oportunidade de ver, e olhar para, uma mulher branca sexualizada e imaginá-la em seu possível destino como escrava"14 (FRIED, 2013, s.p.).

Os nomes das mulheres 'circassianas' também são uma característica marcante: todos eles começam com Z, ou têm Z em algum momento: Zalumma Agra, Aggie Zolutia e Zublia Aggolia são algumas das mulheres circassianas mais famosas do período (FRIED, 2013, s.p.). Outro elemento importante das falsas belezas circassianas são os crucifixos, quase sempre usados em suas fotografias: ele mostra que, apesar de sexualizado e de seu destino terrível, o outro também é virtuoso (FRIED, 2013, s.p.).

Ao longo do século XIX, mais europeus se tornaram familiares $\mathrm{e}$ fascinados pelo Cáucaso e pela aparência dos Circassianos. Mas apesar das mulheres serem a grande maioria exibida nos shows americanos, os homens circassianos também chamavam a atenção. Acreditavase que eram altos, escuros e magros, com longos bigodes, armas prateadas e roupas justas e apertadas. A imagem ao lado, que mostra um homem e duas mulheres circassianas, mostram a grande diferença

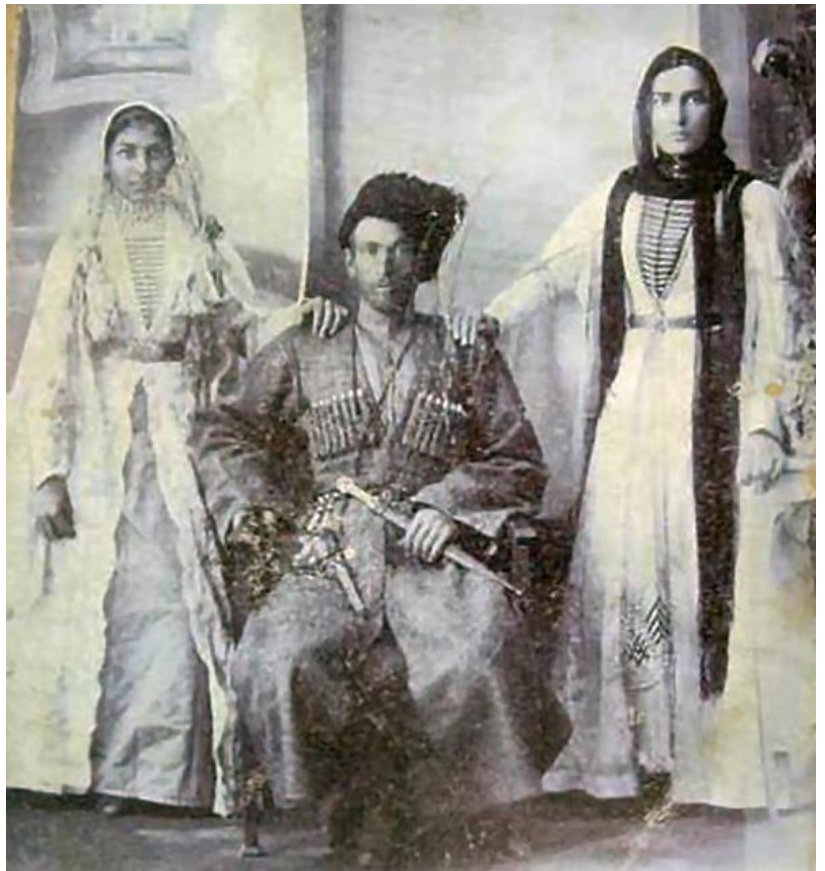

Duas mulheres e um homem circassianos do século XIX. Disponível em: http://i-cias.com/e.o/circassians.htm na vestimenta e no penteado das mulheres desse local em comparação com as mulheres criadas por PT Barnum.

\footnotetext{
13 Original em inglês: "African women were routinely portrayed as sexually lascivious, and therefore in some sense willing and complicit in their sexual exploitation". Tradução minha.

${ }^{14}$ Original em inglês: "It offered the viewer an opportunity to view, and stare at, a sexualized white woman and to imag-ine her possible fate as a slave". Tradução minha.
} 
Edmund Spencer, um viajante britânico e escritor prolífico escreveu na metade do século XIX:

Na primeira aparição de um circassiano, há algo extremamente marcial e dominante: sua aparência majestosa, testa elevada, bigode escuro e barba fluída, sua posição ereta, e a ação livre e irrestrita são calculadas para interessar o estrangeiro a seu favor. Nenhum povo semi-civilizado à vista do mundo tem tão agradável exterior ${ }^{15}$ (KING, 2008, p. 134).

Como observou Charles King, as descrições dos homens circassianos chegavam ao erótico: em 1862, quando dois chefes circassianos, Hadji Hayden Hassan e Kustan Ogli Ismael (curiosamente, nenhum dos nomes tem a letra "Z", diferentemente das atrações de Barum), vieram para a Bretanha promover sua resistência anti-russa, o jornal "Dundee Adversiser" reportou que os homens eram muito bonitos, com vestimentas românticas, cabelos negros, e ares superiores, que os fazia até mesmo pensar no tipo de masculinidade que eles tinham no país deles comparados com os do jornalista (KING, 2008, p. 134).

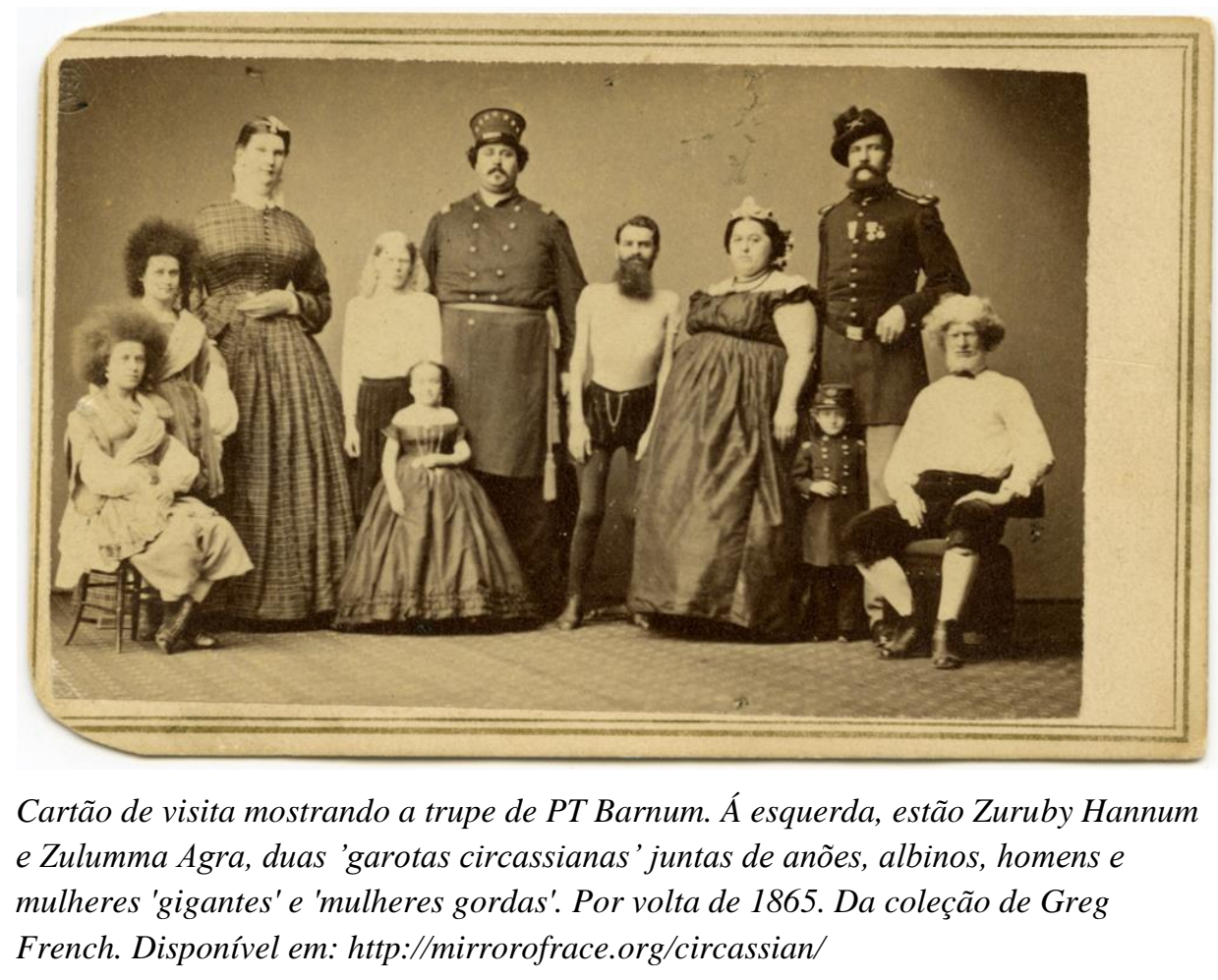

Ser branca, pura e de orıgem caucasiana trouxe tama nao so as muineres, mas também aos produtos que as acompanhavam, e que eram vendidos durante seus shows: cremes para cabelo, pele, óleos e diversos outros produtos que ou vinham do Cáucaso ou usavam

\footnotetext{
${ }^{15}$ Original em inglês: "In the first appearance of a Circassian, there is something extremely martial and commanding: his majestic look, elevated brow, dark moustachio and flowing beard, his erect position, and free unconstrained action, are all calculated to interest the stranger in his favour [...] No half-civilised people in the world display so pleasing an exterior". Tradução minha.
} 
ingredientes do local - obviamente, a grande maioria era feito nos Estados Unidos, com ingredientes também norte-americanos (KING, 2008, p. 136). Dado a fama da palavra "caucasiano", "Cáucaso" e "circassiano", essas passaram ser as palavras chave de um grupo racial superior e de um irresistível mercado consumidor (KING, 2008, p. 136). Além disso, jornais e revistas tinham seus correspondentes para debater "questões circassianas", com discussões relativas à situação política (KING, 2007, p. 244).

Graças a iniciativa de Barnum, até o final da segunda metade do século XIX nenhum museu ou circo era completo sem uma "beleza circassiana": junto dos albinos, mulheres barbadas, anões, e outras pessoas exibidas em shows de horrores, as mulheres da Circássia eram o tipo de raridade que as pessoas pagavam para ver (KING, 2008, p. 136). Mas como observa Robert Bogdan, professor emérito de Ciência Social e Educação da Universidade de Syracuse, as belezas circassianas não eram apresentadas como iguais às outras aberrações. Elas combinavam seu ar exótico, criado por meio das roupas e dos penteados, para exibir uma imagem sensual, atrativa e inteligente, uma mulher que exibisse o misterioso e exótico Oriente Próximo e a reputação dos turcos, os captores dos circassianos. Essa justaposição de beleza e barbária também atraiam os americanos do século XIX (BOGDAN, 2014, p. 241).

John Dingess, um contemporâneo de Barnum, observou na década de 1890 que apesar de mais trinta anos terem se passado desde os primeiros shows das jovens circassianas, elas eram exibidas no Dime Museum - dime, fazendo referência a centavos, eram museus voltados para as classes populares, e o palestrante, quando introduziam as belezas circassianas ao público, invariavelmente anunciam que elas foram trazidas ao país por John Greenwood, para o Museu Americano de Barnum- embora nenhuma delas, curiosamente, fossem mais velhas do que aquelas que atuavam nos shows de Barnum (BOGDAM, 2014, p. 239).

As belezas circassianas não chamariam a atenção para sempre. Suas características tinham sido copiadas tantas vezes que se tornaram banais e deixaram de ser uma das atrações principais. Como as belezas circassianas quase sempre eram mulheres, por algum

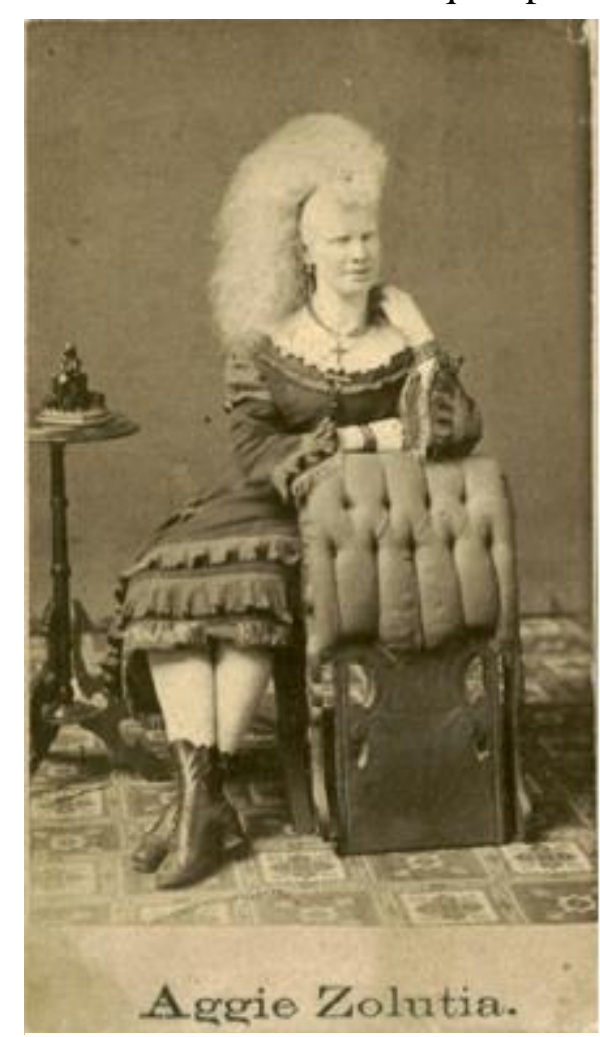

Aggie Zolutia, uma albina apresentada como circassiana. Disponível em: http://www.stevenbolin.com/freaks/circa ssian.html 
tempo os empresários tentaram exibir homens, e começaram a adicionar outras características aos circassianos, como habilidades de ler mentes ou engolir espadas. Outra tentativa de reaver a atenção dada antigamente aos circassianos foi exibir circassianos albinos - ou, melhor dizendo, albinos norte-americanos que fingiam ser circassianos. Essa última inovação teve algum sucesso entre 1880 e 1890. Mas sua fama se extinguiria por volta de 1910, sendo trocadas por outras aberrações.

\section{CONSIDERAÇÕES FINAIS}

Analisando as fotografias das 'belezas circassianas' de Barnum - que não eram nada menos do que mulheres norte-americanas disfarçadas, podemos perceber que o dono de circos e museus se apropriou do cabelo africano das mulheres negras, historicamente associadas com sua posição de sexualidade e escravidão, com as mulheres da Circássia, conhecidas apenas pelo o que a literatura da época trazia de descrições como 'selvagens', 'dóceis' e irremediavelmente levadas à escravidão no seu país de origem.

A posição dos homens e mulheres circassianos que foi adquirida pelo antropólogo alemão Johann Friedrich Blumenbach ao declarar que todos os homens, europeus ou não, tinham origem no Cáucaso, levou a uma revolta norte-americana de que o povo que deu origem ao homem branco estava sendo vítima não apenas de tráfico sexual, mas também de estarem sendo utilizados para 'melhorarem' outras etnias através do casamento. Essas publicações, aliadas aos escritos de Emily Dickinson, Lorde Byron, Lucretia Davidson, Henry Fielding e Voltaire, alimentavam a curiosidade norte-americana - apesar de nenhum deles ter, efetivamente, conhecimento da aparência dos circassianos.

Tirando proveito do interesse americano,

da sua carreira no show de aberrações e seus museus, Barnum, não tendo condições de exibir uma mulher comprovadamente circassiana, apresentou uma mulher que mexia com os mais

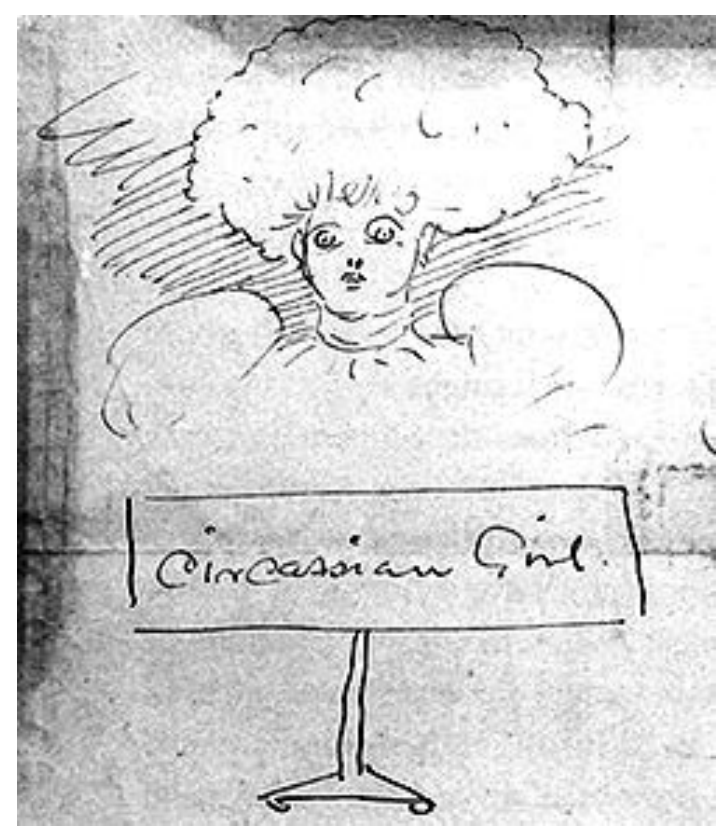

"Circassian Girl and Prize Old Man, Detail". Rascunho do final da década de 1890, por Winslow Homer. Acesso em 25 de Agosto de $2016 . \quad$ Disponível em: http://lostmuseum.cuny.edu/archive/circassiangirl-and-prize-old-man 
íntimos desejos e imaginação dos homens e mulheres dos Estados Unidos. Apesar de utilizar de penteados, roupas e trejeitos que não eram próprias do caucasiano, a imagem das mulheres circassianas que Barnum criou, apesar de terem desaparecido conforme o tempo, não foram esquecidas totalmente na cultura norte-americana: um esboço feito por Winslow Homer (1836 - 1910), pintor e gravurista americano em 1890 mostra uma comparação entre uma garota circassiana com o penteado das famosas mulheres selvagens circassianas (THE, s.d., s.p.)

\section{REFERÊNCIAS BIBLIOGRÁFICAS:}

BOGDAN, Robert. Race, Showmen, Disability, and the Freak Show. In: BANCEL, Nicolas; DAVID, Thomas; THOMAS, Dominic (Orgs.). The Invention of Race: Scientific and Popular Representations. New York: Routledge, 2014.

BRAUNBERGER, Christine. Revolting Bodies: The Monster Beauty of Tattooed Women. NWSA Journal. Maryland: Johns Hopkins University Press, Vol. 12, No. 2 (Verão de 2000), págs. 1-23. Acesso em 7 de Dezembro de 2015. Disponível em: http://www.jstor.org/stable/4316734

FIGAL, Sara. The Caucasian Slave Race: Beautiful Circassian and the Hybrid Origin of European Identity. In: LETTOW, Susanne (Org.). Reproduction, Race, and Gender in Philosophy and the Early Life Sciences. New York: State University of New York, 2014.

FRIED, Gregory. A Freakish Whiteness: The Circassian Lady and the Caucasian Fantasy. Publicado em 15 de Março de 2013. Acesso em 23 de Novembro de 2015. Disponível em: http://mirrorofrace.org/circassian/

FROST, Linda. The Circassian Beauty and the Circassian Slave: Gender, Imperialism, and American Popular Entertainment. In: THOMSON, Rosemarie Garland (Org.). Freakery: Cultural Spectacles of the Extraordinary Body. New York: New York Press, 1996.

HARRIS, Neil. Humbug: The Art of P. T. Barnum. Chicago: University of Chicago Press, 1981.

HORRible Traffic in Circassian Women-Infanticide in Turkey. New York Daily Times, August 6, 1856. Acesso em 23 de Novembro de 2015. Disponível em:

http://lostmuseum.cuny.edu/archive/horrible-traffic-in-circassian

KELLEY, Tina. A Museum to Visit From an Armchair. July 1, 2000. Acesso em 18 de Abril de 2017. Disponível em: http://www.nytimes.com/2000/07/01/nyregion/a-museum-to-visitfrom-an-armchair.html 
KING, Charles. Imagining Circassia: David Urquhart and the Making of North Caucasus Nationalism. The Russian Review. Russia: Editors and Board of Trustees of the Russian Review. Vol. 66, No. 2 (Abril de 2007), págs. 238-255. Acesso em 7 de Dezembro de 2015. Disponível em:

http://www.jstor.org/stable/20620535

KING, Charles. The Ghost of Freedom: A History of the Caucasus. Oxford: Oxford University Press, 2008.

MARTIN, Charles D. The White African American Body: A Cultural and Literary Exploration. New Brunswick: Rutgers University Press, 2002.

MCMASTER, R. D. An Honorable Emulation of the Author of The Newcomes: James and Thackeray. Nineteenth-Century Fiction. California: University of California Press. Vol. 32, No. 4 (Março de 1978), páginas 399-419. Acesso em 07 de Dezembro de 2015. Disponível em: http://www.jstor.org/stable/2932936

MILLER, Cristanne. Reading in Time: Emily Dickinson in the Nineteenth Century. Massachusetts: University of Massachusetts Press, 2012.

NICKELL, Joe. Secrets of the Sideshows. Kentucky: University Press of Kentucky, 2005.

THE Lost Museum Archive. Circassian Girl and Prize Old Man, Detail. Acesso em 25 de Agosto de 2016. Disponível em: http://lostmuseum.cuny.edu/archive/circassian-girl-andprize-old-man

TLOSTANOVA, Madina. Gender Epistemologies and Eurasian Borderlands. United States: Palgrave Macmillan, 2010.

VARIous Tribes of the Human Race. The Illustrated Magazine of Art. New York: Thomas J. Watson Library, The Metropolitan Museum of Art. Vol. 3, No. 16 (1854), págs. 222-226. Acesso em 7 de Dezembro de 2015 Disponível em:

http://www.jstor.org/stable/20538265

VOLTAIRE, François Marie Arouet de (1694-1778). Letters on the English. The Harvard Classics. 1909-14. Acesso em 23 de Novembro de 2015. Disponível em:

http://www.bartleby.com/34/2/11.html

\section{Documentos iconográficos:}

Aggie Zolutia, uma albina apresentada como circassiana. Acesso em 7 de Dezembro de 2015. Disponível em: http://www.stevenbolin.com/freaks/circassian.html 
Cartão de visita mostrando a trupe de PT Barnum. Á esquerda, estão Zuruby Hannum e Zulumma Agra, duas 'garotas circassianas' juntas de anões, albinos, homens e mulheres 'gigantes' e 'mulheres gordas'. Por volta de 1865. Da coleção de Greg French. Acesso em 7 de Dezembro de 2015. Disponível em: http://mirrorofrace.org/circassian/

Cartão de visita mostrando Zoe Meleke, fotografada por Charles Eisenmann por volta de 1885. Papéis da Família Kingsbury. Propriedade da Universidade de Massachussets (UMass Amherst Libraries). Acesso em 7 de Dezembro de 2015. Disponível em: http://scua.library.umass.edu/ead/mums504.xml

"Circassian Girl and Prize Old Man, Detail". Rascunho do final da década de 1890, por Winslow Homer. Acesso em 25 de Agosto de 2016. Disponível em: http://lostmuseum.cuny.edu/archive/circassian-girl-and-prize-old-man

Duas mulheres e um homem circassianos do século XIX. . Acesso em 7 de Dezembro de 2015. Disponível em: http://i-cias.com/e.o/circassians.htm

Foto de cabine mostrando Zula Zinzasa, de 17 anos. Tirada em Trenton, no Missouri. Sem data. Da coleção de Margie Kocina. Acesso em 7 de Dezembro de 2015. Disponível em: https://www.etsy.com/listing/214602238/cabinet-photo-risque-woman-photo-barnum

ARTIGO ENVIADO EM: 29/08/2016

ARTIGO ACEITO PARA PUBLICAÇÃO EM: 18/04/2017 